\title{
Structure of diamond and diamond like carbon thin films grown by hot-filament chemical vapour deposition technique ${ }^{\dagger}$
}

\author{
NITA DILAWAR, SOMNA SAH, B R MEHTA and V D VANKAR \\ Thin Film Laboratory, Department of Physics, Indian Institute of Technology, New Delhi \\ 110016, India
}

\begin{abstract}
Micro-crystalline diamond (MCD) and diamond like carbon (DLC) thin films were deposited on silicon (100) substrates by hot-filament CVD process using a mixture of $\mathrm{CH}_{4}$ and $\mathrm{H}_{2}$ gases at substrate temperature between $400-800^{\circ} \mathrm{C}$. The microstructure of the films were studied by $\mathrm{X}$-ray diffraction and scanning electron microscopy. The low temperature deposited films were found to have a mixture of amorphous and crystalline phases. At high temperatures $\left(>750^{\circ} \mathrm{C}\right)$ only crystalline diamond phase was obtained. Scanning electron micrographs showed faceted microcrystals of sizes up to $2 \mu \mathrm{m}$ with fairly uniform size distribution. The structure of DLC films was studied by spectroscopic ellipsometry technique. An estimate of the amount of carbon bonds existing in $s p^{2}$ and $s p^{3}$ form was obtained by a specially developed modelling technique. The typical values of $s p^{3} / s p^{2}$ ratio in our films are between $1 \cdot 88-8 \cdot 02$.
\end{abstract}

Keywords. Diamond: carbon; chemical vapour deposition; ellipsometry.

\section{Introduction}

Diamond, being an excellent material for various electronic, wear protective, thermal and optical applications has become one of the most studied and strategic materials (Deshpandey and Bunshah 1989). Its large number of applications stem from its unique and excellent properties which arise due to the strong covalent $\mathrm{C}-\mathrm{C}$ bonding between its constituent atoms. Synthetic diamond films are produced mainly by chemical vapour deposition (CVD) methods by decomposition of hydrocarbon gases. The films have particles which often appear as octahedral, cubo-octahedral or multiply twinned particles according to the deposition conditions (Matsumoto and Matsui 1983; Matsumoto 1985; Kim et al 1990). On the other hand DLC films are predominantly amorphous with varying amounts of $s p^{3}$ and $s p^{2}$ coordinated carbon atoms in a random network.

The desire to understand the properties of these films has stimulated a number of structural investigations and attempts at modelling the microstructure of DLC matrix (Stenhouse and Grant 1978; Fink et al 1983; Beeman et al 1984; Savvides 1985). The structure and morphology of these films are crucially dependent on the parameters employed for deposition. An accurate control over these parameters is, therefore, absolutely essential.

We have employed a hot-filament CVD technique to grow good quality microcrystalline diamond and DLC films. The advantages of this technique over other CVD techniques are described elsewhere (Deshpandey and Bunshah 1989). The films have been characterized for structure, morphology and various carbon phases by X-ray diffraction, SEM and spectroscopic ellipsometry techniques. The real and imaginary 
parts of the dielectric constant were used to model the amount of $s p^{3}$ and $s p^{2}$ coordinated carbon atoms in DLC films by use of Kramer-Kronig relations as applied to a specially developed modelling technique.

\section{Experimental}

The hot-filament CVD set-up used for deposition of diamond/DLC films is shown in figure 1 . We used a $0.25 \mathrm{~mm}$ tungsten wire coil held at temperatures $>2000^{\circ} \mathrm{C}$ for the decomposition of the incoming gases. The temperature of the substrates, which were placed in the close vicinity of the filament, increased substantially by radiation. Additional heat was provided by the second filament placed below the substrate. This assisted in obtaining an independent control of the substrate temperature. A mixture of $\mathrm{CH}_{4}$ and $\mathrm{H}_{2}$ was used as the source gas and released from a single nozzle placed above the filament. The films were deposited on $p$-type single crystal $\mathrm{Si}(100)$ substrates. The substrates were pretreated by scratching with $0.5 \mu \mathrm{m}$ diamond paste and later ultrasonically treated in a diamond powder suspension. This causes cavitation erosion of the

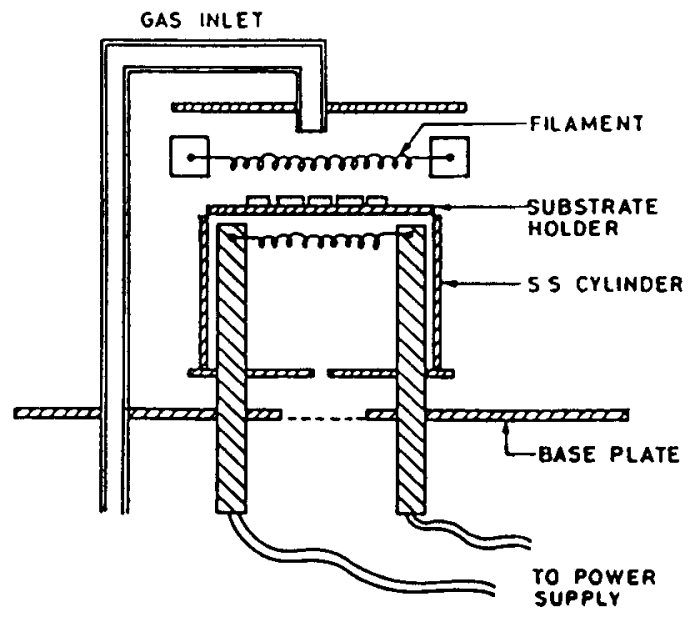

Figure 1. Schematic set-up of hot-filament CVD system used for the present work.

Table 1. Typical deposition parameters used to grow diamond and diamond like carbon thin films.

\begin{tabular}{lcc}
\hline Parameter & Diamond films & DLC films \\
\hline Source gases & $\mathrm{CH}_{4}+\mathrm{H}_{2}$ & $\mathrm{CH}_{4}+\mathrm{H}_{2}$ \\
Filament temperature & $>2000^{\circ} \mathrm{C}$ & $>2000^{\circ} \mathrm{C}$ \\
Substrate temperature & $750-800^{\circ} \mathrm{C}$ & $400-700^{\circ} \mathrm{C}$ \\
Working pressure & $10-50$ Torr & $1-30$ Torr \\
Total gas flow & $150-200$ sccm & $150-200$ sccm \\
Gas ratio $\left(\mathrm{CH}_{4}: \mathrm{H}_{2}\right)$ & $1 \cdot 5: 130-1 \cdot 5: 90$ & $1: 10-1: 100$ \\
Substrate & $\mathrm{Si}(100) p$-type & $\mathrm{Si}(100)$-type \\
\hline
\end{tabular}


substrate surface and thus provides low free energy sites for a faster rate of nucleation. The substrates were then degreased and cleaned in trichloroethylene and acetone ultrasonically. The typical deposition parameters are as given in table 1 .

\section{Results and discussion}

Figures $2 \mathrm{a}$ and $\mathrm{b}$ show the glancing angle $\mathrm{X}$-ray diffraction patterns for diamond and DLC films respectively. Figure $2 a$ shows the presence of (111) and (220) orientations of the polycrystalline diamond phase. No amorphous phase was observed within the limits of the experiment. Figure $2 b$ shows a broad amorphous feature. Figures $3 a-c$ show the SEM micrographs of these films. The micrographs for diamond films showed both rounded as well as well faceted micro-crystallites in the films. The crystallite morphology of the diamond films during growth was highly sensitive to the growth conditions and reflected the growth mechanism. The micrographs showed that
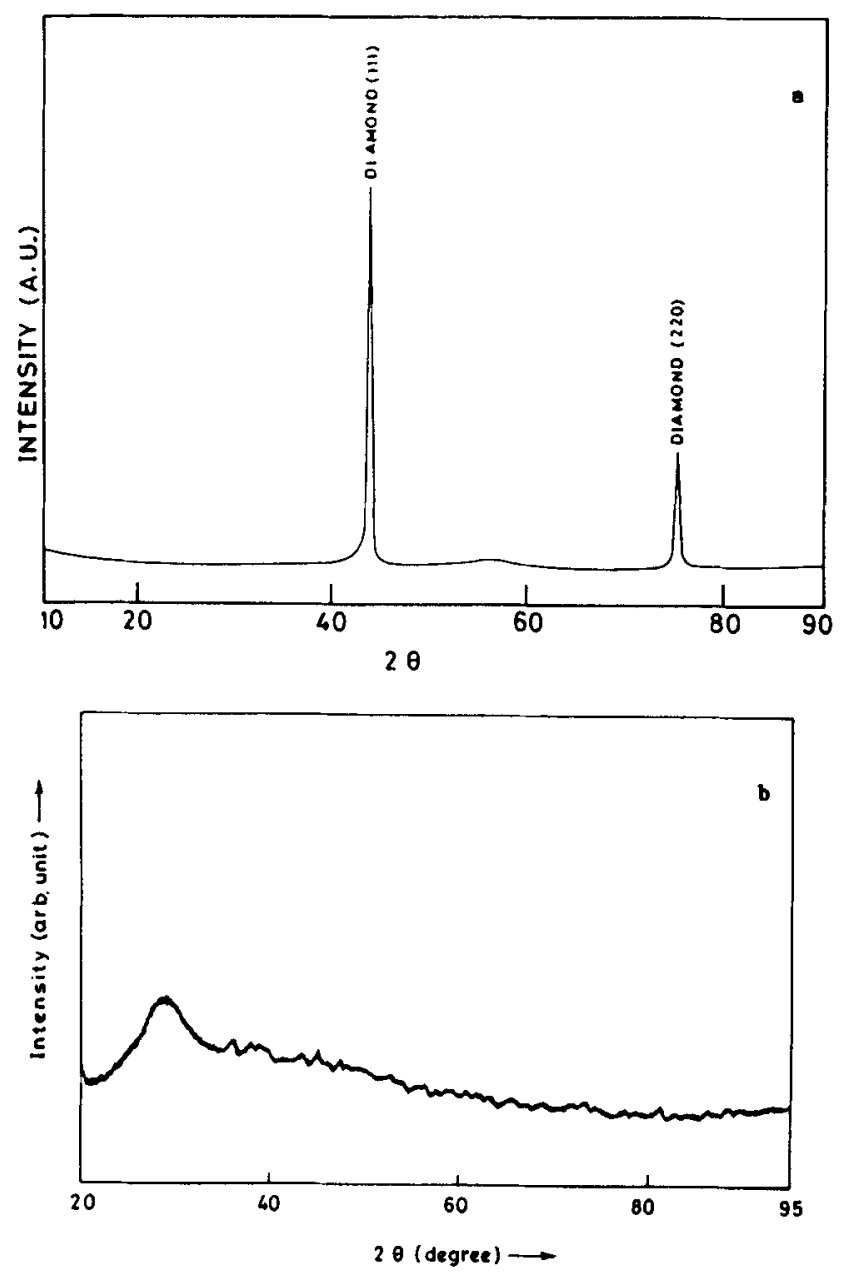

Figure 2. a. X-ray diffraction pattern of a typical micro-crystalline diamond film and b. X-ray diffraction pattern of a typical DLC film. 

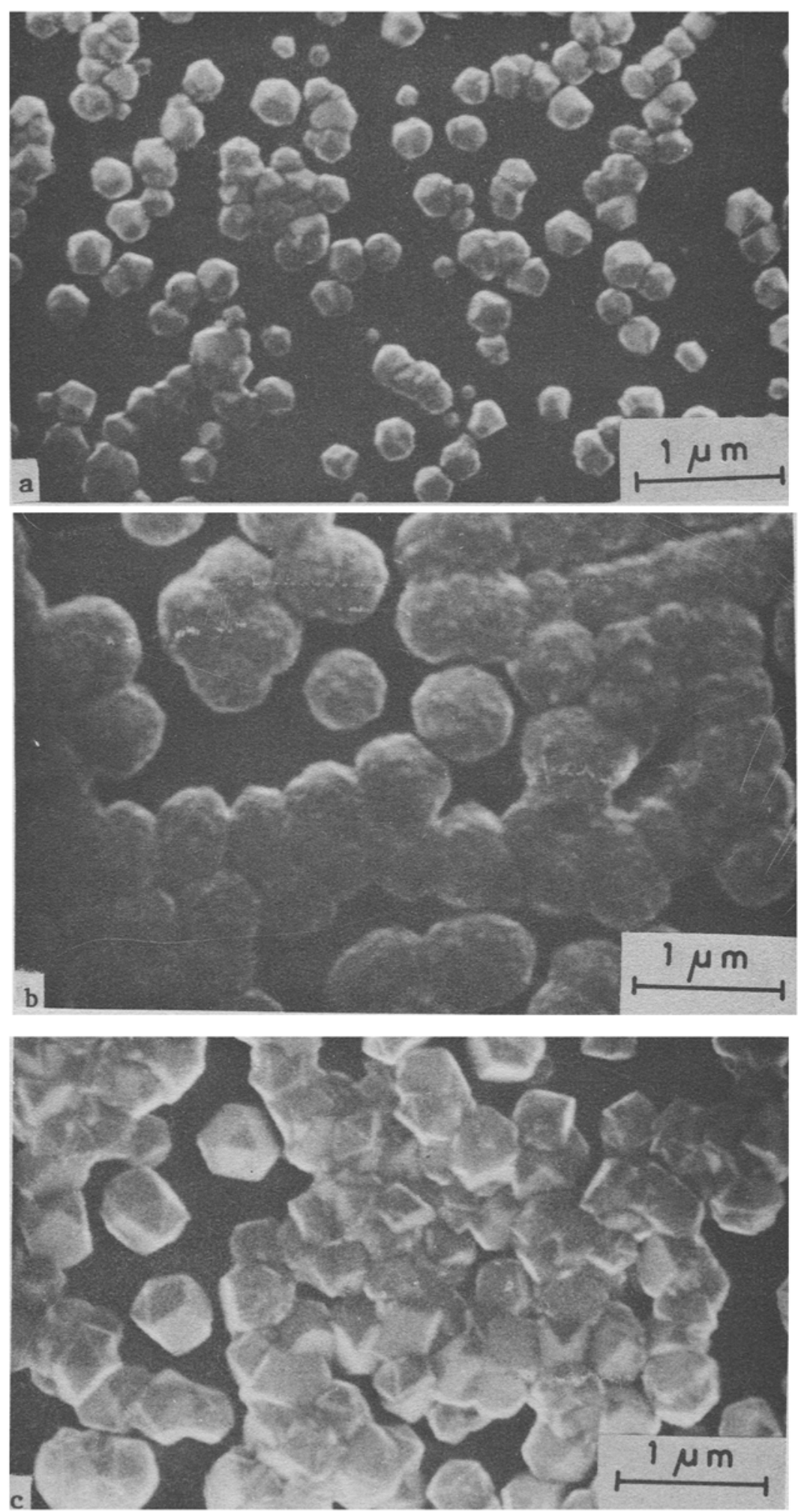

Figure 3. Scanning electron micrographs of diamond thin films: a. diamond thin film at initial stages of growth, $\mathbf{b}$. diamond thin film of a at later stages of growth and $\mathbf{c}$. film deposited at lower $\mathrm{CH}_{4} / \mathrm{H}_{2}$ ratio showing faceted growth of diamond micro-crystallites. 
rounded crystallites were essentially diamond polyhedra with very large number of faces which gave the rounded look. These shapes were observed only in films prepared with a very high $\mathrm{CH}_{4} / \mathrm{H}_{2}$ flow ratio. This may be due to lower rates of etching of amorphous and non-diamond phases being deposited along with the diamond microcrystallites. This results in incorporation of defects and $\mathrm{C}=\mathrm{C}$ bonds in addition to the $s p^{3}$ hybridized covalent bonds. On the other hand, by increasing the hydrogen concentration the non-diamond carbon was removed and the active species reaching the substrate surface oriented themselves into tetrahedral configuration before forming the saturated covalent bonds with the growing film. Thus we obtained well faceted crystallites with defects incorporated only at the grain boundaries. The films were $1.5-2.0 \mu \mathrm{m}$ thick as measured with the 'Talystep'. The average particle size was about $1.5 \mu \mathrm{m}$ as observed from the SEM micrographs.

Figure 4 shows the variation of real and imaginary parts of the dielectric constant of the diamond film. $\varepsilon_{1}$ variation shows no special feature in the range $(1.5-5.0 \mathrm{eV})$ of the experiment. This is a characteristic feature of the diamond phase. In addition, $\varepsilon_{1}$ remains positive throughout the spectral range showing the absence of any graphitic phase. The $\varepsilon_{2}$ variation is directly related to the interband transitions. The $\sigma-\sigma^{*}$ transitions in diamond occur after $7 \mathrm{eV}$ whereas graphitic carbon gives structure in $\varepsilon_{2}$ at $4.8 \mathrm{eV}$. The $\varepsilon_{2}$ spectrum shows no structure around $4.8 \mathrm{eV}$ which indicates the absence of graphite phase in our films. The $7 \mathrm{eV}$ structure could not be observed as it was much beyond the range of the instrument. Figure 5 shows the typical $\varepsilon_{1}$ and $\varepsilon_{2}$ spectra of a DLC thin film. The spectra show larger spectral dependence and higher absorption as compared to that shown in figure 4 . The structure in $\varepsilon_{2}$ spectrum near $3.0 \mathrm{eV}$ is a characteristic feature of amorphous carbon phase.

A modelling technique has been developed to estimate the $s p^{3} / s p^{2}$ ratio in our films by using experimentally observed ellipsometric data. In this method, the effective
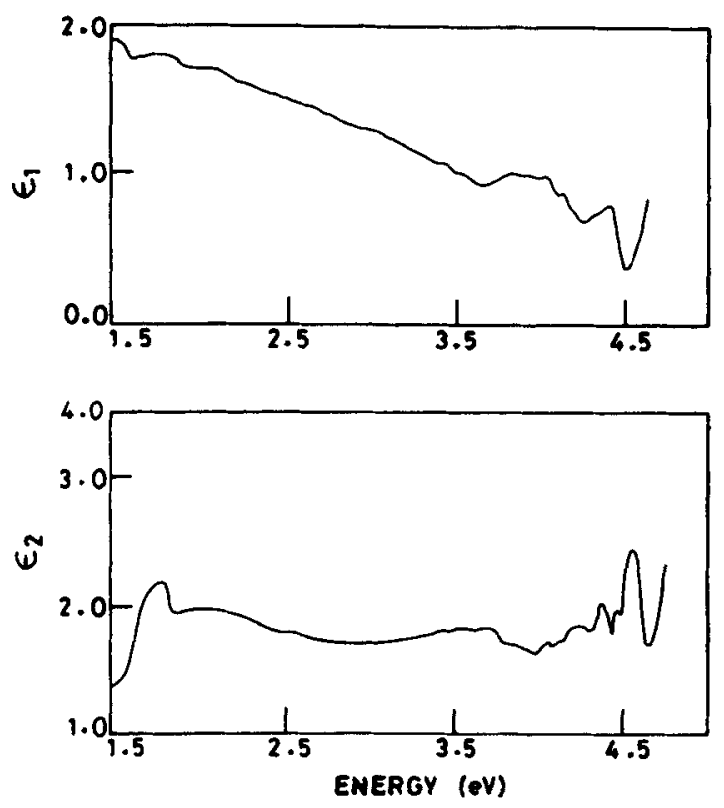

Figure 4. $\varepsilon_{1}$ and $\varepsilon_{2}$ variation of a diamond thin film in $1.5-5.0 \mathrm{eV}$ energy range. 
number of $\pi$ electrons/carbon atom were calculated from the $\varepsilon_{2}$ obtained by gaussian fit (Demicheles and Pirri 1992; Wemple and Didomenico 1971) to the experimentally determined $\varepsilon_{2}$ data. A void fraction of $20 \%$ and hydrogen concentration of $25 \%$ in the DLC films has been assumed and these values have been used to calculate the total number of electrons/unit volume in the DLC matrix. The detailed method is described elsewhere (Sah et al 1996).

The typical values obtained for our films varied from 1.88-8.02 depending on the deposition conditions as shown in table 2.

Table 2 shows that the $s p^{3} / s p^{2}$ ratio for films deposited at higher pressure was lesser than for the films deposited at lower pressures. The films deposited at higher pressures tended to have more graphitic carbon atoms than those deposited at lower working pressures. Similar results have been observed with films prepared using $\mathrm{C}_{2} \mathrm{H}_{2}$ as the source gas (Sah et al 1996). This may be because the mean free path of the active radical species produced by decomposition of the hydrocarbon gas decreases as the working pressure increases. This leads to lower supersaturation of active radical species near the substrate surface although the supersaturation of the various gas species increases. Consequently, the amount of $s p^{3}$ coordinated carbon atoms decreases. The amount of hydrogen in the source gases also influences $C s p^{3}: C s p^{2}$ ratio by increasing/decreasing
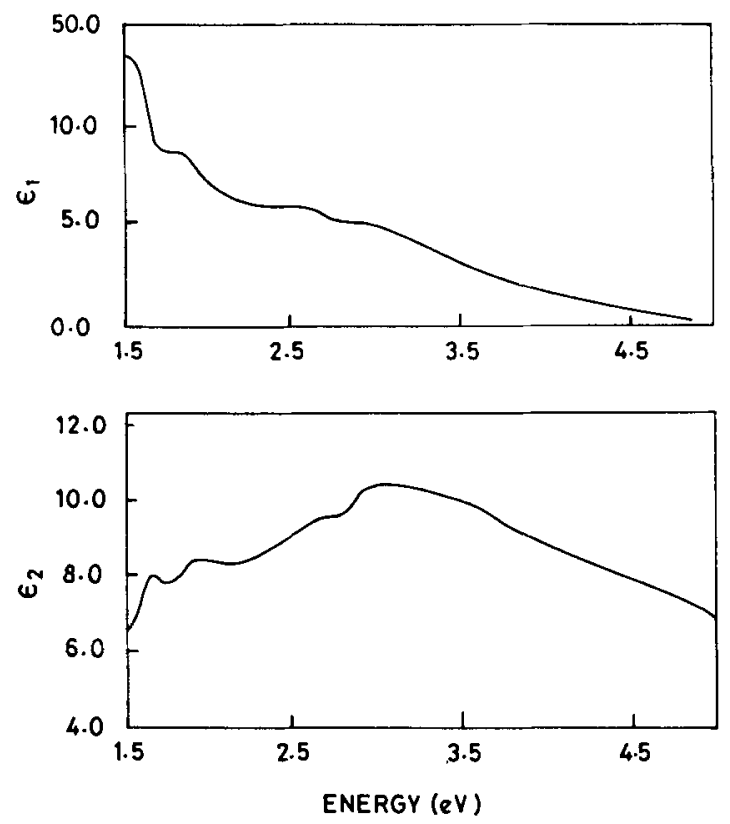

Figure 5. $\varepsilon_{1}$ and $\varepsilon_{2}$ variation of a DLC film in $1 \cdot 5-5 \cdot 0 \mathrm{eV}$ energy range.

Table 2. Dependence on deposition parameters of $s p^{3} / s p^{2}$ ratios obtained for DLC films.

\begin{tabular}{lccccc}
\hline $\begin{array}{l}\text { Sample } \\
\text { name }\end{array}$ & $\begin{array}{c}s p^{3} / s p^{2} \\
\text { ratio }\end{array}$ & $\begin{array}{c}\text { Source } \\
\text { gas }\end{array}$ & $\begin{array}{c}\text { Hydrocarbon/ } \\
\mathrm{H}_{2} \text { ratio }\end{array}$ & $\begin{array}{c}\text { Substrate } \\
\text { temp. }\end{array}$ & $\begin{array}{c}\text { Pressure } \\
\text { (torr) }\end{array}$ \\
\hline M1 & 1.88 & $\mathrm{CH}_{4}$ & $2 \cdot 5: 100$ & $800^{\circ} \mathrm{C}$ & 30 \\
$\mathrm{M} 2$ & 8.02 & $\mathrm{CH}_{4}$ & $5: 70$ & $750^{\circ} \mathrm{C}$ & 10 \\
\hline
\end{tabular}


the passivation of dangling bonds on the surface and in the bulk of the DLC matrix. It has been observed that higher hydrogen concentrations lead to higher $s p^{3} / s p^{2}$ ratios.

\section{Conclusions}

Good quality microcrystalline diamond thin films have been deposited on $\mathrm{Si}(100)$ single crystal pretreated substrates. The crystallite morphology and growth rates have been studied with respect to the deposition parameters. Consequently, deposition parameters have been optimized to obtain the required crystalline quality. Using the experimentally determined real and imaginary parts of dielectric constants, a theoretical model has been used to estimate the ratio of $s p^{3} / s p^{2}$ coordinated carbon atoms in DLC films. The results have been correlated to the deposition parameters employed. It has been found that the films have high $s p^{3} / s p^{2}$ ratio corresponding to good quality DLC thin films.

\section{Acknowledgements}

Authors thank Prof. K L Chopra for helpful discussions and Dr Chattar Singh for the SEM micrographs. Two of the authors (ND and SS) thank CSIR for providing senior research fellowships. Authors also thank the Department of Science and Technology, New Delhi for financial assistance.

\section{References}

Beeman D, Silverman J, Dynds R and Anderson M R 1984 Phys. Rev. B30 870

Demicheles F and Pirri C F 1992 Phys. Rev. B45 14364

Deshpandey C V and Bunshah R F 1989 J. Vac. Sci. Tech. A47 2294

Fink J, Muller-Heinzerling I and Pfluger J 1983 Solid State Commun. 47687

Kim J S, Kim M H, Park S S and Lee J Y 1990 J. Appl. Phys. 673354

Matsumoto S 1985 J. Mater. Sci. Lett. 4600

Matsumoto S and Matsui Y 1983 J. Mater. Sci. 181785

Sah S, Dilawar N, Mehta B R and Vankar V D 1996 Thin Solid Films (communicated)

Savvides N 1985 J. Appl. Phys. 58518

Stenhouse B J and Grant P J 1978 J. Non-Cryst. Solids 27247

Wemple S H and Didomenico M 1971 Phys. Rev. B3 1338 